\title{
Analysis of Vegetable Supply Chains of Supermarkets in Sri Lanka
}

\author{
Manoshi Perera, Sarath S. Kodithuwakku and Jeevika Weerahewa*
}

\begin{abstract}
The emergence of supermarkets may provide an alterative avenue through which vegetables can move from the producer to the consumer. To date, no research has been conducted to determine the functions of vegetable supply chains of supermarkets in Sri Lanka. This study aimed to fill this gap while ascertaining whether the emergence of supermarkets has created vegetable supply chains that are different from existing traditional supply chains and if so, to examine whether such alternative supply chains are comparatively more efficient and effective. The research was conducted in the form of Case studies. To establish the existing supermarket related vegetable supply chains, supermarkets were selected using the purposive sampling technique. A sample of actors involved in a given supermarket supply chain was chosen via the Snowball sampling technique. The findings of the study revealed that supermarkets do create alternative supply chains of vegetables; however, these alternative supply chains are created only with respect to supermarkets with a large number of outlets. Such supply chains deem to be comparatively more efficient and effective than traditional supply chains in terms of paying a higher price for vegetables, having a higher degree of transparency, presence of quality consciousness and accountability, passing down of quality signals, involvement of less number of intermediaries and occurrence of comparatively low post harvest losses. In some locations, the emergence of the particular supermarket supply chain has contributed to increase the level of competition among buyers leading to an increase in the farm gate price offered by the traditional supply chains. However, the benefits yielded by the farmers vary depending on the context. Due to the uncertainty in relation to price and quantity, farmers were not motivated to improve their production practices. At present, the amount of vegetables passing through supermarket supply chains deem to be comparatively very low, thus the policy focus should be to improve the efficiency and effectiveness of traditional supply chains while aiding farmers to better integrate with these new markets.
\end{abstract}

\footnotetext{
* The authors are affiliated to the Department of Agricultural Economics and Business Management, Faculty of Agriculture, University of Peradeniya.
} 


\section{Introduction}

Traditional vegetable supply chains in Sri Lanka that engage in moving vegetables from the producer to the consumer are prone to various sources of inefficiencies. Farmers in vegetable producing areas are unable to attract competitive buyers (Gunatilake et al., 1992). Many of the farms are located in relatively isolated areas, a considerable distance from improved roads making access to competitive markets difficult and costly (Hettige and Senanayake, 1992; Kodithuwakku, 2000; Schermerhon, 1986). Lack of bargaining power along with various credit bound relationships with the buyers has lead to farmers being exploited during the transaction (Hettige and Senanayake, 1992; Kodithuwakku, 2000; Rupasena et al., 2001, Shanmugarathnam, 1984), where most of the farmers become 'price takers' (Gunatilake et al., 1992; Hettige and Senanayake, 1992; Kodithuwakku, 2000; Schermerhon, 1986). The majority of the farmers are smallholders (Gunatilake et al., 1992; Hettige and Senanayake, 1992; Kodithuwakku, 2000; Schermerhon, 1986) and hence, inability to obtain a fair price for their produce results in farmers not being able to sustain their livelihood. The structure of the traditional vegetable supply chains is such that there are a large number of intermediaries (e.g. vegetable collectors, transporting agents, commission agents etc.) between the producer and the consumer (Hettige and Senanayake, 1992;

Kodithuwakku, 2000; Rupasena et al., 2001). Addition of the marketing margins of all these intermediaries coupled with almost 30 to 40 percent of the vegetables being wasted as post harvest losses have eventually resulted in producers receiving a very low price for their produce while at the other end the consumers are compelled to pay a highly inflated price for their purchases (Hettige and Senanayake, 1992; Kodithuwakku, 2000).

Supermarkets are currently growing at a fast rate in Sri Lanka. There is an emerging trend to establish outlets in other areas of the country by leading supermarkets which were initially concentrated in locations in and around Colombo. The main supermarket chain in Sri Lanka is currently registering a growth rate of about 3 to 4 outlets per month. It is also apparent that single outlet supermarkets are also emerging in urban and sub urban areas of the country.

Amidst the inefficient traditional vegetable supply chains, the emergence of supermarkets may open an alternative avenue through which vegetables can move from the producer to the consumer. The study conducted aimed to examine the structure and operations of vegetable supply chains of supermarkets in Sri Lanka in order to ascertain whether the emergence of supermarkets has 
created alternative supply chains that are different from traditional vegetable supply chains and if so, examine whether these alternative supermarket supply chains are comparatively more efficient and effective as opposed to existing traditional supply chains in moving vegetables from the producer to the consumer.

\section{Methodology}

The study was carried out in the form of a case study as the case study approach has a considerable ability to generate answers to questions such as "Who?", "What?", "Why?" and "How?" that enable the researcher to gain a rich understanding of the processes being enacted within a given context while drawing attention to differences and similarities (Gummesson, 1991; Morris and Wood, 1991; Robson, 1993; Yin, 1994).

The sample of supermarkets was selected purposively where supermarkets were chosen so as to capture the variability of the population in terms of; the number of outlets belonging to each supermarket, their geographical location, ownership structure and the number of years in the business. In situations where it was considerably difficult to identify all the members of the desired population, a sample of various actors involved at various levels of the vegetable supply chain of the supermarket was selected using the snowball sampling. In this particular sampling technique, the researcher initially made contact with one or two members of the population and asked these members to identify some other members belonging to the same population. Once the researcher made contact with these newly identified members, those members where asked to further name some other members of the population. This process was continued until the desired sample size was reached. Once the existing supermarket related vegetable supply chains are established, the supply chains of supermarkets were compared and contrasted with major traditional vegetable supply chains of the country. A detailed description of the sample is provided in appendix 2.

Information on the vegetable supply chain of supermarkets was obtained using primary data collected via semi-structured interviews and observations while information on traditional vegetable supply chains was obtained by reviewing relevant literature supplemented by key informant interviews.

\section{Results and Discussion}

The structure of different supermarket vegetable supply chains operating in Sri Lanka is provided in figure 1. Each interface of the supermarket related vegetable supply chain was analyzed via the matrix of interactions and the findings are illustrated in appendix 1. 
Supermarkets with a small number of outlets (one or two outlets) procure their vegetable requirement from the traditional wholesale market through an intermediary (i.e. vegetable supplier). Vegetables move along traditional vegetable supply chains until they reach the wholesale market. Therefore, such supply chains (supply chain C) are mere extensions of the existing traditional vegetable supply chains.

Supermarkets with a fairly large number of outlets ( 7 or 8 outlets) procure their up-country vegetable requirement from vegetable collectors who bring vegetables to the Central Purchasing Unit (CPU) of the supermarket. Once the vegetable order is faxed to the vegetable collectors, they travel around the up-country area purchasing vegetables from farmers at the roadside. They then engage in sorting the vegetables and those which are of superior quality are sold to the supermarket while those rejected by the supermarket are sold at the wholesale market or to certain retailers willing to buy them at a slightly lower price. Since the vegetable collectors pay the farmers the same farm gate price offered by traditional vegetable supply chains and they purchase vegetables from the roadside in an ad-hoc manner, the existence of such supply chains (supply chain D) is not beneficial to the farmer as it does not pay a higher price for their produce nor provide them with a guaranteed market.

The supermarket with the highest number of outlets (i.e. 64) has regional vegetable collecting centres located in vegetable producing areas. Farmers as well as vegetable collectors bring vegetables to these collecting centres (supply chains A and B). Before doing so, they obtain an order from the person in charge at the regional collecting centre the previous day. The vegetable requirements of the supermarket are conveyed to these regional vegetable collecting centres and accordingly vegetable orders are issued to the farmers and the vegetable collectors. Upon arrival, the supermarket employees working at the regional vegetable collecting centre inspect the vegetables and whatever is of suitable quality is bought while the rest is returned (usually such returns are very low).

The supermarket does not adhere to quality standards stipulated by formal certificates. Rather, the quality parameters actually adopted are mostly related to the physical attributes of the produce such as size, colour, texture and whether the produce is free from pest and disease attacks. Farmers sell the remaining part of their harvest (which is not of the quality required by the supermarket) to vegetable collectors in the traditional market or send them 




Figure 1: Structure of Vegetable Supply chains of Supermarkets operating in Sri Lanka.

Note: CPU - Central Purchasing Unit

to commission agents at the wholesale market through transporting agents. Vegetable collectors sell rejects to retailers in the near vicinity at a slightly lower price. The purchasing price of the vegetables for the day is decided by the head office in Colombo and is conveyed to these regional vegetable collecting centres while ensuring that the price is higher than the price

offered by traditional vegetable supply chains. The selected vegetables are loaded into standard crates belonging to the supermarkets. Afterwards the vegetables are transported in freezer trucks to the Central Purchasing Unit (CPU) from which they are dispatched to individual outlets. The operations of the supply chain B is similar to that of $\mathrm{D}$, where the vegetable collector 
pays the farmer the same price prevailing in traditional vegetable supply chains and purchases vegetables in an ad-hoc manner. However, the supermarket vegetable supply chain A, where the supermarket buys directly from the farmer and sells directly to the consumer is different from the existing traditional vegetable supply chains and thus can be termed as an 'alternative' supply chain created by the supermarket with the largest number of outlets.

Majority of the vegetables moving through traditional supply chains pass via the main wholesale markets in Dambulla and Colombo. Therefore, traditional vegetable supply chains that move through the Dambulla and Colombo wholesale markets (illustrated in figure 2) were chosen for comparison purposes. The 'alternative' vegetable supply chain (A) created by the supermarket with the largest number of outlets was compared with traditional vegetable supply chains and the findings were as follows.

It was observed that the price offered to the farmers by the vegetable supply chain of the supermarket is higher than that offered by traditional vegetable supply chains. Since the supermarket purchases only vegetables of superior quality and since they have to compete with traditional vegetable supply chains, it is essential that the price offered by the supermarket be higher than the price offered by the traditional vegetable supply chains in order to stimulate the farmers to sell their harvest to the supermarket instead of to the individuals involved in the traditional supply chains.

The transparency in the transaction between the buyer and the farmer is relatively low among traditional vegetable supply chains. The commission agents tend to quote a price to the farmers which is lower than the price for which the vegetables were actually sold at the wholesale market. They also reduce a certain amount of the weight, stating that the vegetables have been damaged and dehydrated while being transported. Since the farmer is not present at the transaction, he has no choice but to accept the stated figures. Thus, the commission agents are known to take undue advantage of the farmers. This situation is especially prevalent in the Colombo wholesale market (Hettige and Senanayake, 1992; Kodithuwakku, 2000; Rupasena et al, 2001).In comparison, the farmer is present during the quality inspection process at the regional collecting centre of the supermarket and spot cash payments are made when the vegetables are purchased. Therefore, there is a higher degree of transparency in the transaction at the farmer level with respect to the supermarket vegetable supply chain compared to the traditional vegetable supply chains. 


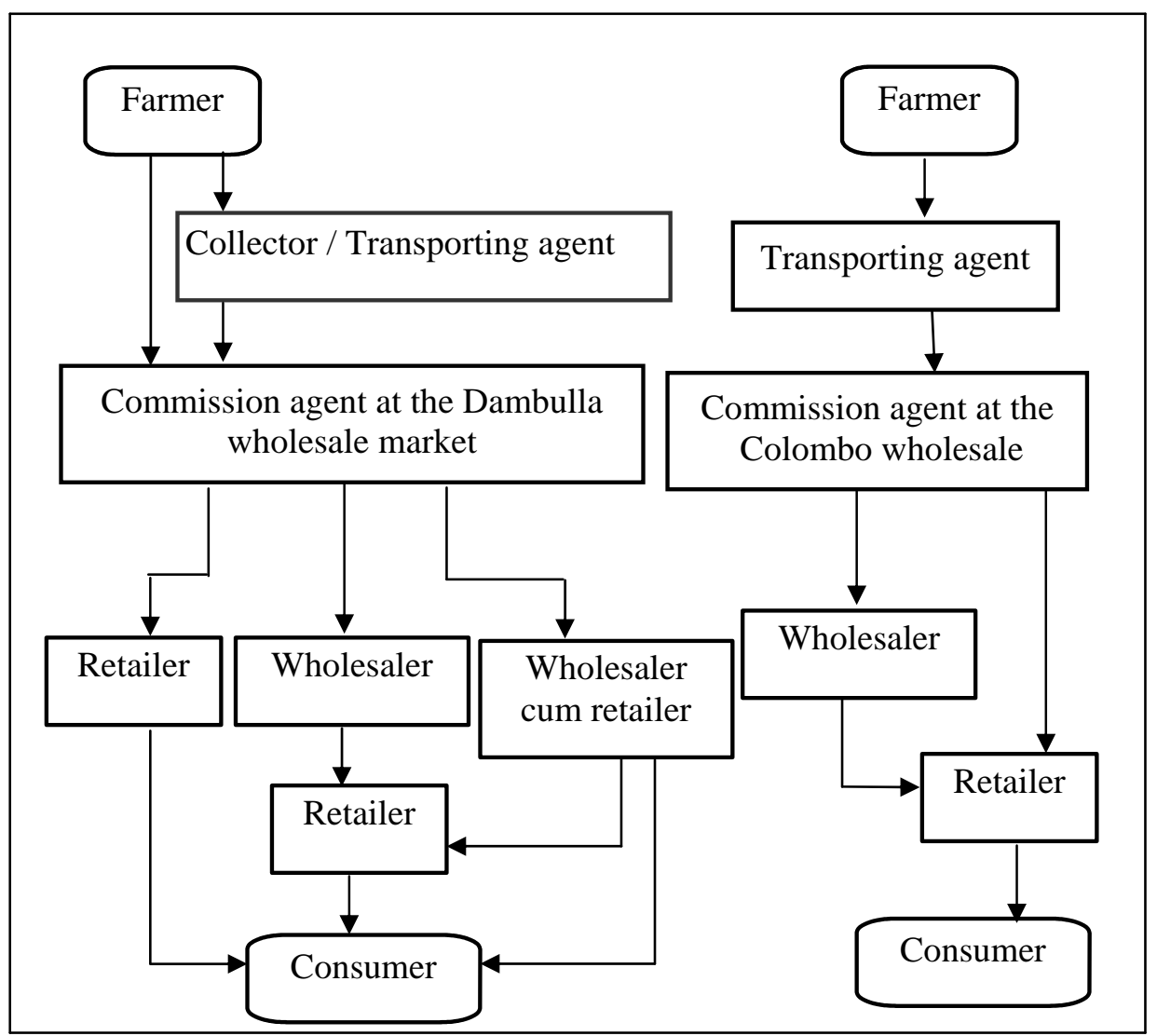

Figure 2: Structure of Traditional Vegetable Supply chains operating in Sri Lanka.

Individuals such as transporting agents and "Nattamies" (who engage in loading and unloading) do not acquire title (i.e. ownership) for the vegetables they handle. Therefore they are neither conscious nor feel

themselves accountable for the quality of the produce. Due to the lack of quality consciousness and accountability, transporting agents

overload the sacks of vegetables (sometimes with commodities other than vegetables) and "Nattamies" tend to drop vegetable sacks from the top of the transporting vehicles while handling them, not being bothered about the damage caused on impact (Hettige and Senanayake, 1992; Kodithuwakku, 2000; Rupasena et al., 2001). These practices have eventually led to much of the vegetables being wasted as post 
harvest losses. In contrast, quality consciousness and accountability is prevalent throughout the supermarket vegetable supply chain. Farmers are conscious of the quality since otherwise their produce will be rejected at the regional vegetable collecting centre. Supermarkets are conscious of the quality because they cater to a consumer segment which is quality conscious. The presence of quality consciousness is evident from the manner in which they handle the vegetables and the use of crates and freezer trucks while transporting.

In the traditional vegetable supply chains, quality signals are not being passed down to the farmers. Farmers are paid by the weight and they are not given a premium price for quality. Thus, their main focus is to increase the weight. This has in turn led to some farmers engaging in certain mal-practices such as putting stones and inferior quality vegetables in the middle part of the sacks of vegetables (Hettige and Senanayake, 1992; Rupasena et al., 2001). On the other hand, only vegetables of superior quality are purchased from farmers at the regional vegetable collecting centres and they are paid a premium price for such vegetables. Therefore, quality signals are being passed down to farmers along the vegetable supply chains of the supermarket and it ensures that only inputs of superior quality enter the supermarket vegetable supply chain.

The number of intermediaries involved is comparatively high in the traditional vegetable supply chains as opposed to the supply chain of the supermarket where the supermarket is the only intermediary present between the producer and the consumer.

Post harvest losses are negligible along the vegetable supply chain of the supermarket ( 1 to 3 percent), whereas in the traditional vegetable supply chains the post harvest losses are as high as 35 to 40 percent (Hettige and Senanayake, 1992; Kodithuwakku, 2000; Rupasena et al., 2001). This is a serious problem with regard to the traditional vegetable supply chains, as a considerable portion of the total harvest is lost and the cost is ultimately born by the producer and the consumer.

In conclusion it can be stated that the emergence of supermarkets by itself do not create 'alternative' supply chains of vegetables that are different from the existing traditional vegetable supply chains. However, as the number of outlets belonging to the supermarket increases, they acquire the necessary economies of scale to adopt a vegetable supply chain of their own where they buy 
directly from the farmer and sell directly to the consumer. Such supply chains are efficient and effective compared to traditional vegetable supply chains in terms of paying a higher price, higher degree of transparency in the transaction, presence of quality consciousness and accountability throughout the supply chain, quality signals being passed down, less number of intermediaries involved in the supply chain and occurrence of comparatively low post harvest losses.

Such supermarket supply chains have reduced the level of monopsony in traditional vegetable supply chains by creating an alternative market for farm produce. It allows farmers to sell the superior portion of their harvest at a higher price. At the same time, it was found that in Hanguranketha, the prevalence of the particular supermarket supply chain has prompted the buyers attached to traditional supply chains to increase the price offered to farmers. However, this situation was not prevalent in Nuwara-Eliya due to insignificance of the amount of vegetables being purchased by the vegetable collecting centre of the supermarket.

It should be noted that the supermarket which adopts the above mentioned supply chain that purchases vegetables directly from farmers, also procure a part of their vegetable requirement from vegetable collectors (i.e. supply chain B in figure 1). This seems to be the most prominent system in practice at the vegetable collecting centre in Nuwara-Eliya. In such situations, the benefits of the higher price offered by the supermarket is retained by the intermediary (i.e. vegetable collector) and neither price nor quality signals are passed down to farmers.

Farmers are not required to adopt special production practices in order to sell their produce to the supermarket supply chain and even the small scale farmers have the ability to sell their produce at the regional vegetable collecting centre. However, it is only the farmers in the near vicinity of the regional vegetable collecting centre who have the ability to access the supermarket supply chain. Those living further away and in areas with poor transport facilities find it difficult and costly to bring their produce to the regional vegetable collecting centre of the supermarket. Therefore, it is the accessibility to the regional vegetable collecting centre that determines which farmers have the ability to sell their produce to the vegetable supply chain of the supermarket. 
Further, the supermarket does not have any formal nor verbal contract agreements with the farmer which states that they would purchase a certain quantity of their produce at a pre-agreed price at a future date. The farmers obtain an order for a given quantity of vegetables from the regional vegetable collecting centre on the day prior to harvesting and they are paid a price based on the price prevailing in the market during the particular day. Due to the prevalence of uncertainty in relation to the price that will be paid and the quantity that will be purchased by the vegetable collecting centre of the supermarket at the time of harvesting, farmers being risk averters, are not willing to adopt production practices to improve the quality of the produce. The adoption of such practices will increase the cost of production and the farmers may incur a loss if they are unable to sell their harvest to the supermarket as the traditional chains do not offer a premium price for quality.

While the supermarket chain with the largest number of outlets has given rise to an efficient and effective supply chain where the supermarket buys directly from the farmer and sells directly to the consumer, the benefits yielded by farmers vary according to the conditions prevalent in the locality.
On the other hand, data obtained from the Sri Lanka Integrated Survey (SLIS 2001) revealed that only about 3 percent of the households in Sri Lanka receive a monthly household income which is compatible with the income received from those shopping from supermarkets (Weerahewa and Kodithuwakku, 2004). Out of the consumers shopping from supermarkets, only about 33 percent procure their vegetable requirement from the supermarket outlet (Wickramarachchi, 2004) while others prefer to procure their vegetables from traditional retail outlets (e.g. from the 'Pola'). The managers of the supermarket also stated that vegetables are sold at the supermarket for product availability purposes and that they do not obtain a very high profit from them and thus do not allocate much shelf space for vegetables. Therefore, we may assume that the quantity of vegetables moving along these supermarket supply chains is comparatively insignificant as opposed to the quantity moving along the traditional channels. Thus, the policy focus should aim to enhance the efficiency and effectiveness of traditional supply chains while aiding the small scale farmers to better integrate with these new markets. 
Authors gratefully acknowledge the financial assistance provided by the International Food Policy Research Institute (IFPRI) to carry out this study.

\section{References}

Gummesson, E. (1991). Qualitative Methods in Management Research. United States of America: Sage Publications Inc.

Gunatilake,G., M. Perera, R.A.M.C. Wanigaratne, R.E. Fernando, W.D. Lakshman, J.K.M.D. Chandrasiri and R.D. Wanigaratne. (1992). Rural Poverty in Sri Lanka: Priority Issues and Policy Measures. Asian

Development Review.10.

Hettige, S. T. and S. M. P. Senanayake. (1992). Highland Vegetable Production and Marketing Systems. A report prepared for Agriculture Cooperative Development International/USAID.

Kodithuwakku, K.A.S.S. (2000). Analysis of Tomato Supply Chains in the Kandy district. An unpublished report prepared for University of Peradeniya.
Morris, T. and S. Wood. (1991). Testing the Survey Methods: Continuity and Change in British Industrial Relations. Work Employment and Social Society. 5:82-259 as quoted in Saunders, M., P. Lewis and A. Thornhill. (1997). Research Methods for Business Students. London: Pitman publishing.

Robson, C. (1993). Real World Research, Oxford, Blackwell as quoted in Saunders, M., P. Lewis and A. Thornhill. (1997). Research Methods for Business Students. London: Pitman publishing.

Rupasena L.P., R. Bandara and T. Ravichandran. (2001). Study of Agricultural Marketing Information Systems (Matale district). Colombo: Hector Kobbekaduwa Agrarian Research Institute.

Schermerhon, R. W. (1986). A Comparative Analysis of Fruit and Vegetable Marketing in Developing Countries. GTS Report, Postharvest Institute for Perishables/USAID, Vol.82.

Shanmugarathnam, N. (1984). Sri Lanka's "New" Economic 
Policies and Agriculture. Social Scientist. Vol. 12.

Weerahewa, J. and K.A.S.S. Kodithuwakku. (2004). Evolution of food retail chains in Sri Lanka. A research report prepared for the International Food Policy Research Institute IFPRI, Washington DC.

Wickramarachchi, V. D. (2004). Profiling and Assessment of Supermarket Customers. An undergraduate report. Department of Agricultural
Economics and Business Management, Faculty of Agriculture, University of Peradeniya.

Yin, K. (1994). Case Study

Research: Design and

Methods. Sage Publications

Inc.:USA. 


\section{Appendix 1}

Matrix of interaction along supermarket vegetable supply chains

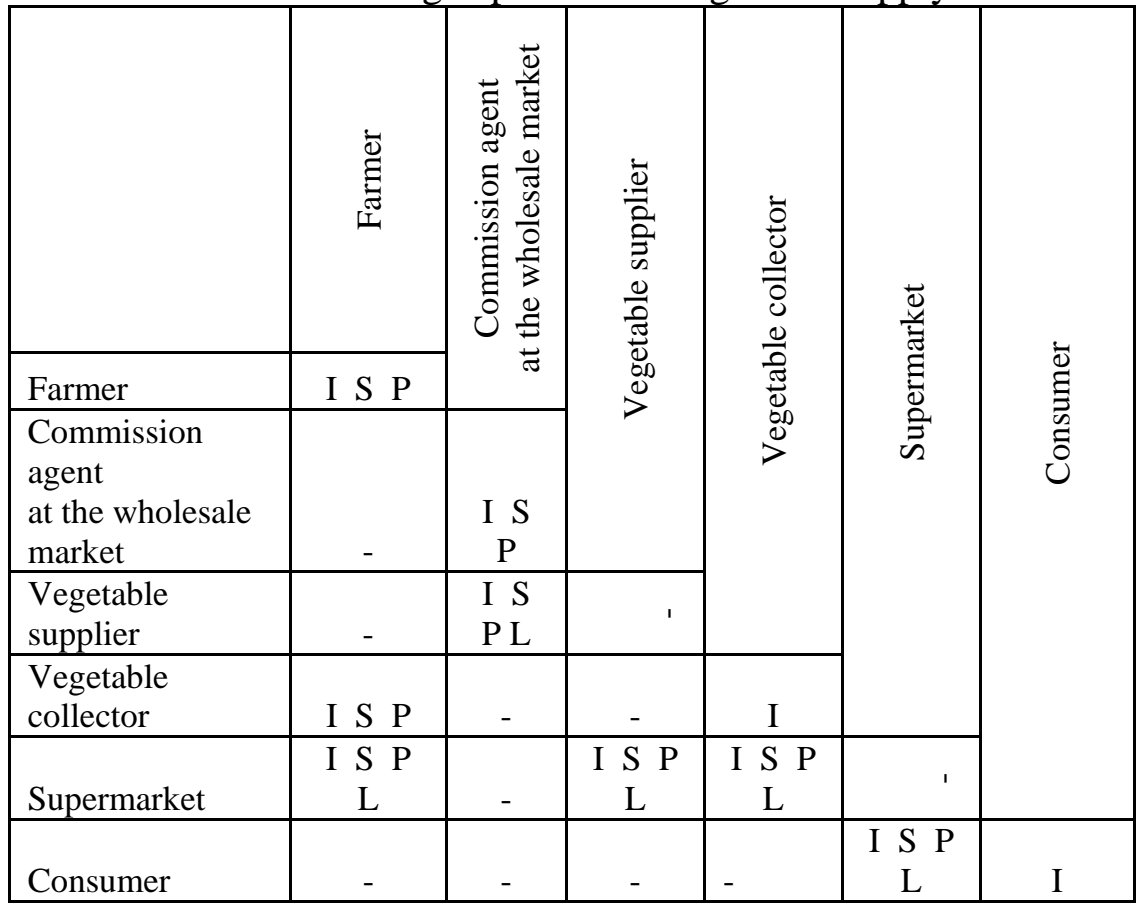

Note:

I - Information relations (information flows accompanying the interaction)

S- Exchange of goods and services (exchange of goods and services)

P- Power relations (dominance of one partner over the other)

L- Legal relation (laws and agreements regulating the exchange of goods and services) 


\section{Appendix 2}

Summary of description of the sample

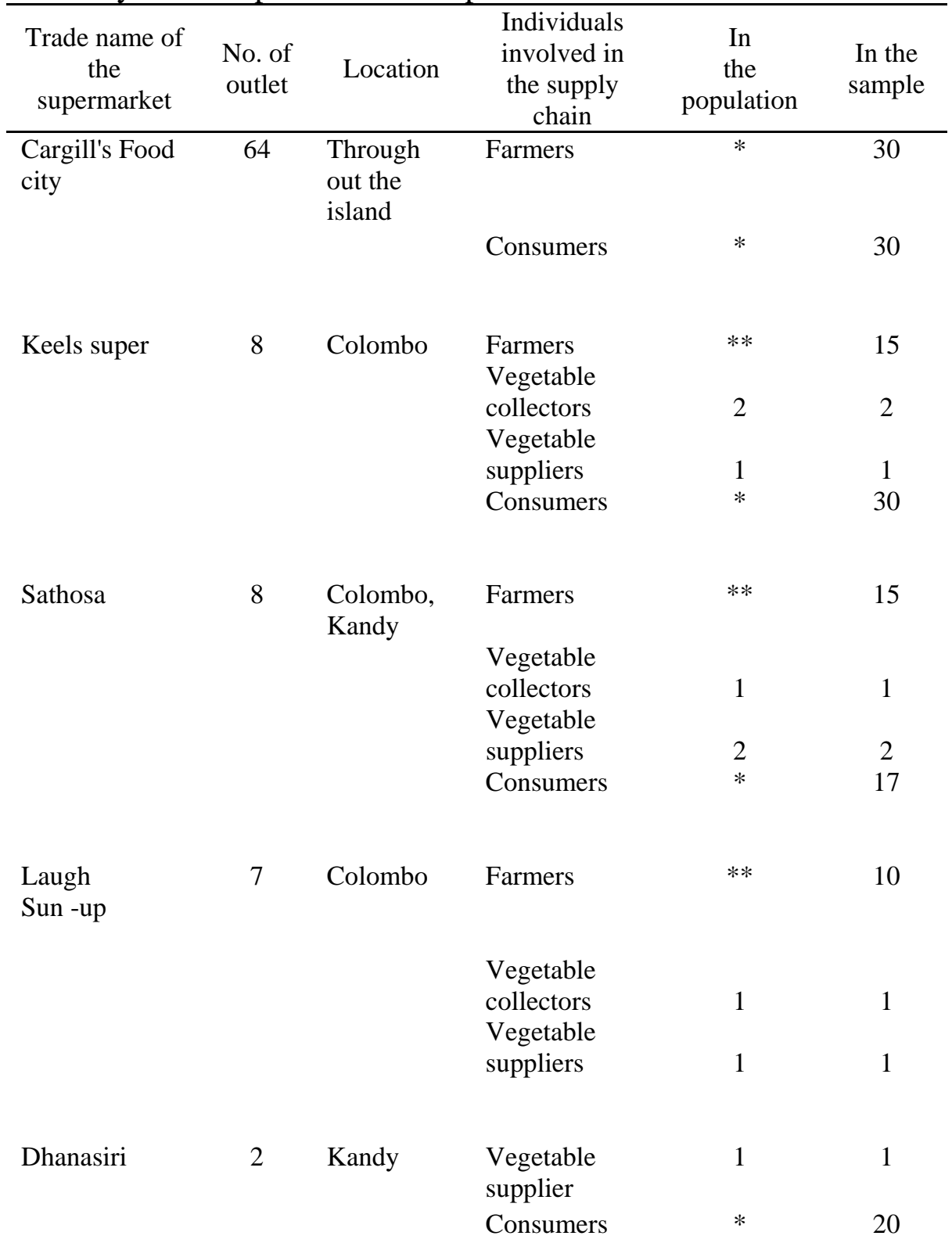






\begin{tabular}{|c|c|c|c|c|c|}
\hline \multirow[t]{2}{*}{$\begin{array}{l}\text { Royal garden } \\
\text { mall }\end{array}$} & 1 & Kandy & $\begin{array}{l}\text { Vegetable } \\
\text { supplier }\end{array}$ & 1 & 1 \\
\hline & & & Consumers & $*$ & 30 \\
\hline
\end{tabular}

* Information not provided by the supermarket

** Cannot be estimated 